artigos técnicos

\title{
Avaliação da qualidade do ar na Região Metropolitana de Campinas: determinação de metais pesados no material particulado (PM10) e contribuição das fontes de emissão \\ Air quality evaluation in Campinas Metropolitan Region: determination of heavy metals in particulate matter (PM10) and contribution of emission sources
}

\author{
Silvana Moreira e Ariston da Silva Melo Junior \\ Professora Titular do Depto.de Saneamento e Ambiente (FEC/ \\ UNICAMP). \\ Atuação na área de Poluição Ambiental com ênfase no estudo \\ de metais pesados. \\ Especialista em Fluorescência de Raios X. \\ Faculdade de Engenharia Civil, Arquitetura e Urbanismo, Dep- \\ to de Saneamento e Ambiente,
}

Endereço:* Av. Albert Einstein, 951, Caixa Postal 6021, CEP 13083-952, Campinas, SP

\section{RESUMO}

Devido a sua localização e importância, foram instalados três postos de monitoramento para coleta do material particulado em suspensão na atmosfera na RMC. Os locais escolhidos foram: Avenida Anchieta (centro de Campinas), distrito de Barão Geraldo e Paulínia. Em todos os postos foram coletadas as duas frações (grossa e fina) do material particulado. No posto de amostragem no Centro de Campinas foram observados valores acima do considerado como regular para a qualidade do ar. De forma geral os valores de PM10 para Paulínia e para o Centro de Campinas foram superiores aos de Barão Geraldo. Utilizando a técnica de SR-TXRF foram identificados e quantificados 19 elementos (Al; Si; P; S; Cl; K; Ca; Ti; V; Cr; $\mathrm{Mn}$; Fe; $\mathrm{Co}$; Ni; Cu; $\mathrm{Zn}$; $\mathrm{Se}$; $\mathrm{Br}$ e $\mathrm{Pb}$ ). Empregando a análise de componentes principais e a análise de cluster, foi possível agrupar estes elementos em função da fonte emissora.

Palavras-chave: poluição atmosférica; material particulado; metais pesados; qualidade do ar; fontes de emissão.

\section{ABSTRACT}

Due to its location and importance three monitoring sites for particulate material in suspension on the atmosphere were installed in the Campinas Metropolitan Region. The sampling sites chosen were: Av. Anchieta (Campinas downtown), Barão Geraldo district and Paulínia city. In all locations, particulate material was collected in two fractions, coarse and fine. In the Campinas downtown site values above the regular air quality established by CETESB (150 $\mu$ g.m-3) was observed. In a general way the PM10 values for Paulínia and Campinas center were higher than Barão Geraldo. Using SR-TXRF technique, nineteen elements (Al; Si; P; S; Cl; K; Ca; Ti; V; Cr; Mn; Fe; Co; Ni; Cu; Zn; $\mathrm{Se} ; \mathrm{Br}$ and $\mathrm{Pb}$ ) in coarse and fine fractions were identified and quantified. Applying principal component analysis and cluster analysis to the results, it was possible to assemble its according the emission sources.
Key words: Atmospheric pollution; particulate matter; heavy metals; air quality; emission sources

\section{INTRODUÇÃO}

Existe atualmente uma preocupação por parte de pesquisadores e governantes com a atmosfera, pois é o meio no qual ocorrem transformações e/ou alterações que podem trazer danos significativos para o clima do nosso planeta. A emissão de gases poluentes na atmosfera tem aumentado significativamente, devido ao crescimento da população e dos parques industriais nas grandes cidades.

$\mathrm{O}$ ar é denominado poluído quando contém uma ou mais substâncias químicas em concentrações suficientes para causar danos à flora e à fauna. Uma das principais fontes de poluição presente na atmosfera é o material particulado, que não constitui uma espécie química definida, mas um conjunto de partículas no estado sólido ou líquido, capaz de permanecer em suspensão.

As relações do material particulado com o meio ambiente são bastante complexas, pois para descrever seu comportamento é necessário determinar a concentração, o tamanho, a composição química, a fase e a morfologia.

Diferentes tecnologias têm sido testadas com o objetivo de caracterizar o material particulado na atmosfera, sendo de grande importância a determinação da concentração dos elementos químicos presentes no material particulado, e não apenas a determinação da massa total das frações grossa e fina.

Conhecendo-se a origem do material particulado, é possível avaliar o impacto de cada fonte, e desta forma estas informações podem servir de parâmetro para formular uma política de controle dessas fontes poluidoras.

Desta forma neste trabalho foi empregada a técnica de Fluorescência de Raios X por Reflexão Total com Radiação Síncrotron (SR-TXRF) para a análise do material particulado coletado na Região Metropolitana de Campinas. Empregando a SR-TXRF foi possível identificar as fontes de emissão e determinar a contribuição destas, nas duas frações do material particulado.

\section{METODOLOGIA}

Para o trabalho foram montados três postos de coleta de material particulado, sendo dois nas dependências das instalações das estações de monitoramento ambiental da Companhia de Tecnologia de Saneamento Ambiental (CETESB), sendo o primeiro na região central da cidade de Campinas e o segundo no município de Paulínia (área de influência da região de Campinas). O terceito posto de amostragem foi instalado no Campus da UNI- 


\section{- artigos técnicos}

CAMP, no distrito de Barão Geraldo (MELO JUNIOR, 2007).

\subsection{Locais de amostragem}

O primeiro coletor foi montado no centro de Campinas, loca-lizado na avenida Anchieta, dentro das dependências da escola pública Carlos Gomes, este local representa uma área densamente urbanizada com grande fluxo de veículos (Figura 1).

O segundo posto alocado na estação da CETESB em Paulínia encontra-se localizado na praça Monsenhor Emilio J. Salin (Figura 2). Este posto coletor é importante por representar uma região com grande concentração de indústrias metalúrgicas e químicas, incluindo a Refinaria de petróleo de Paulínia (REPLAN) da PETROBRAS.

O terceiro posto coletor de material particulado foi montado nas dependências da estação meteorológica do Centro de Pesquisas Meteorológicas e Climáticas Aplicadas a Agricultura (CEPAGRI), na Universidade Estadual de Campinas (UNICAMP), localizado dentro da área do campo experimental da Faculdade de Engenharia Agrícola (FEAGRI), no distrito de Barão Geraldo. A Figura 3 mostra a área da estação meteorológica, sendo que em destaque localiza-se o abrigo para o sistema de coleta de material particulado.

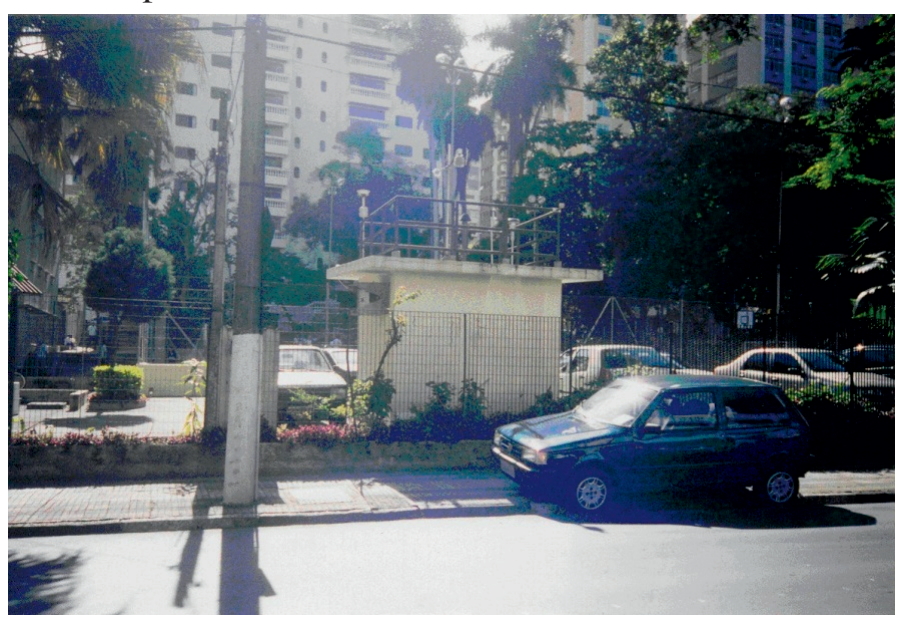

Figura 1 - Vista geral do posto instalado na Av. Anchieta, centro da cidade de Campinas.

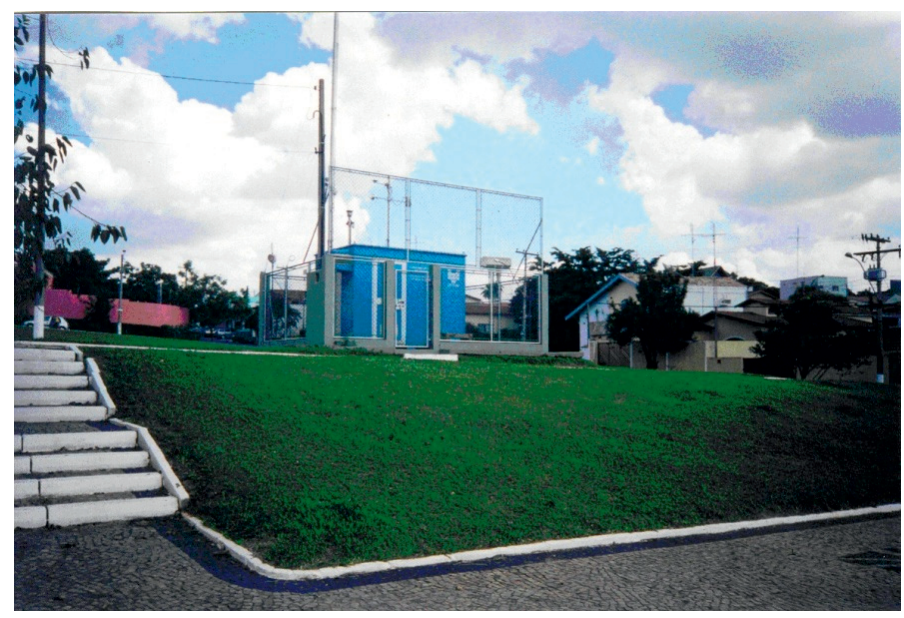

Figura 2 - Posto coletor localizado em Paulínia na praça Monsenhor Emilio J. Salin.

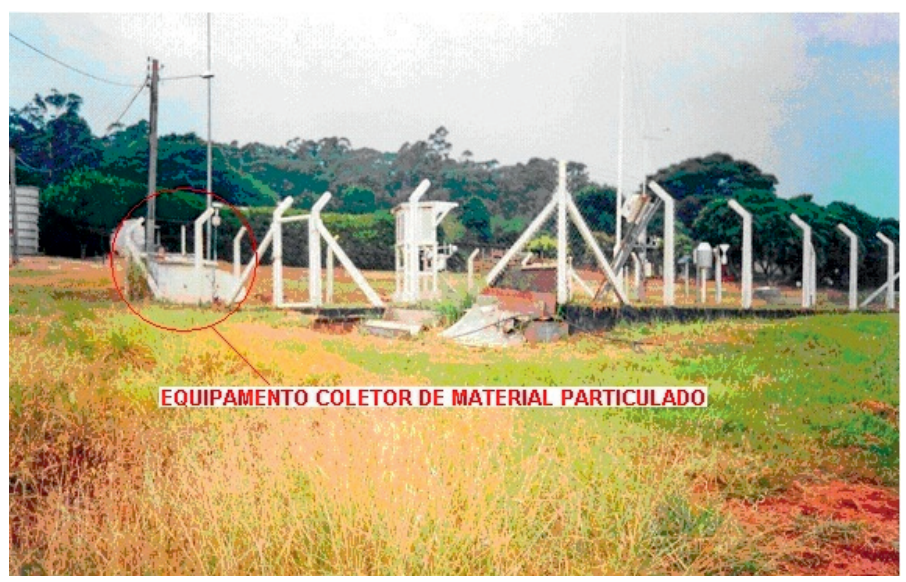

Figura 3 - Vista geral do posto de coleta localizado na FEAGRI-UNICAMP.

\subsection{Cronograma de coleta}

As amostras foram coletadas semanalmente em cada um dos postos. O período de 24 horas de amostragem foi empregado com a finalidade de se comparar os valores de PM10 deste trabalho com os da CETESB.

As coletas iniciaram-se em 18 de outubro de 2005 no posto de Barão Geraldo e terminou em 18 de março de 2006 no posto do centro de Campinas. No total foram obtidas 21 amostras para a fração grossa e 21 para a fração fina em cada posto coletor, ou seja, num total de 126 amostras. Todas as leituras foram feitas em triplicata.

Dados climáticos como: temperatura máxima, umidade relativa e precipitação pluviométrica, foram obtidas junto ao Centro de Pesquisas Meteorológicas e Climáticas Aplicadas a Agricultura (CEPAGRI) da Universidade Estadual de Campinas.

\subsection{Sistema de amostragem}

O sistema de amostragem adotado é o de filtração seqüencial, ou Amostrador de particulado Fino e Grosso (AFG). Com este sistema pode-se obter as frações grossa e fina, que correspondem às frações inaláveis superior e inferior, respectivamente. Em cada sistema coletor montado foi construído um suporte para os dois filtros em série AFG (PARKER et al. 1997), o qual foi colocado em uma tubulação de admissão (inlet), projetado para capturar partículas com diâmetro aerodinâmico de até 10 m. O comprimento do inlet é desenhado para proporcionar uma deposição uniforme da partícula no primeiro filtro de coleta. $\mathrm{Na}$ amostragem, a entrada do ar está localizada à uma altura de 2,15 $\mathrm{m}$ do solo (Figura 4a). O AFG e o inlet são ligados à uma bomba de vácuo e a um totalizador de volume para a medida do volume de ar captado (Figura 4b).

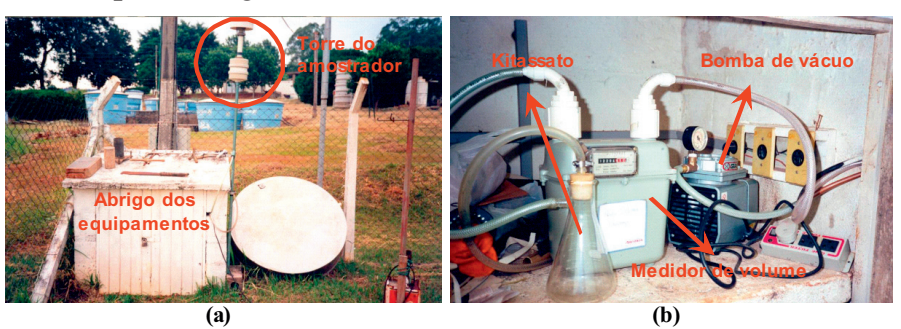

Figura 4 - Vista externa (a) e interna (b) da estação montada na Campus da UNICAMP.

A f

tros

fina

par

$\mathrm{O}$

\section{Ad}

e d

vim
son

pel

2.4
lise 


\section{artigos técnicos}

A fração grossa do material particulado é coletado nos filtros com diâmetro de poros de $8,0 \mu \mathrm{m}$ (coleta de partículas com diâmetro aerodinâmico entre 2,5 e $10 \mu \mathrm{m}$ ) e, a fração fina, em filtros com diâmetro de poros de $0,4 \mu \mathrm{m}$ (coleta de partículas com diâmetro aerodinâmico menor que 2,5 $\mu \mathrm{m}$ ). O AFG encontra-se instalado na parte interna da torre do amostrador, conforme pode-se observar na Figura 5a.

A determinação da massa do material particulado coletado e depositado nos filtros é realizada através da análise gravimétrica. A concentração de PM10 é determinada pela soma das massas contidas na fração fina e grossa, dividida pelo volume de ar medido pelo totalizador de volume.

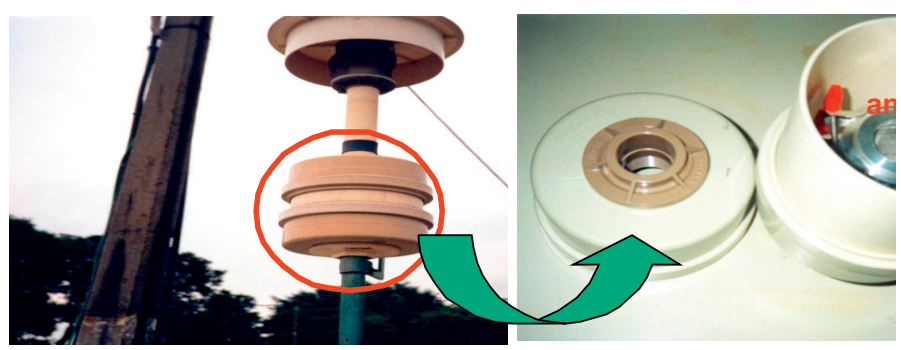

(a)

(b)

Figura 5 - Vista externa da torre do amostrador (a). Amostrador instalado dentro do receptáculo da torre (b).

2.4. Preparo das amostras de material particulado para análise por SR-TXRF

Para a análise por SR-TXRF, o filtro amostrado foi colocado em um béquer, onde se adicionaram $1 \mathrm{~mL}$ de ácido nítrico (HNO3) e $3 \mathrm{~mL}$ de ácido clorídrico $(\mathrm{HCl})$ concentrados. Em seguida o béquer contendo o filtro foi colocado em um banho de ultra-som para a remoção do material particulado (KLOCKENKÄMPER et al., 1992). A suspensão foi mantida a $100^{\circ} \mathrm{C}$ durante cerca de 20 minutos ou até uma redução considerável do volume. O material resultante foi recuperado em $10 \mathrm{~mL}$ utilizando água deionizada e desmineralizada (Milli-Q).

A cada $1 \mathrm{~mL}$ de amostra foram adicionados $100 \mu \mathrm{L}$ de uma solução de Gálio (102,5 mg.L-1) usado como padrão interno, resultando em uma concentração de 9,32 mg.L-1 do padrão em cada amostra (MOREIRA e FAZZA, 2008). Ao final do preparo $5,0 \mu \mathrm{L}$ da solução resultante foi pipetada sob o suporte de lucite (SCHMITT et al, 1987) e seca com auxílio de uma lâmpada infravermelha (SAVAGE e HASWELL, 1998).

2.5. Arranjo experimental da fluorescência de raios $X$ por reflexão total com excitação por radiação síncrotron (SRTXRF)

Na estação experimental de fluorescência de raios $X$ (figura 6a), para a excitação das amostras foi utilizado um feixe branco de radiação síncrotron. Na detecção dos raios $\mathrm{X}$ foi utilizado um detector semicondutor de $\mathrm{Si}(\mathrm{Li})$, com janela de berílio de $8 \mu \mathrm{m}$ de espessura, uma área ativa de $30 \mathrm{~mm} 2$, com resolução de 165 eV (5,9 keV) (LNLS, 2009).

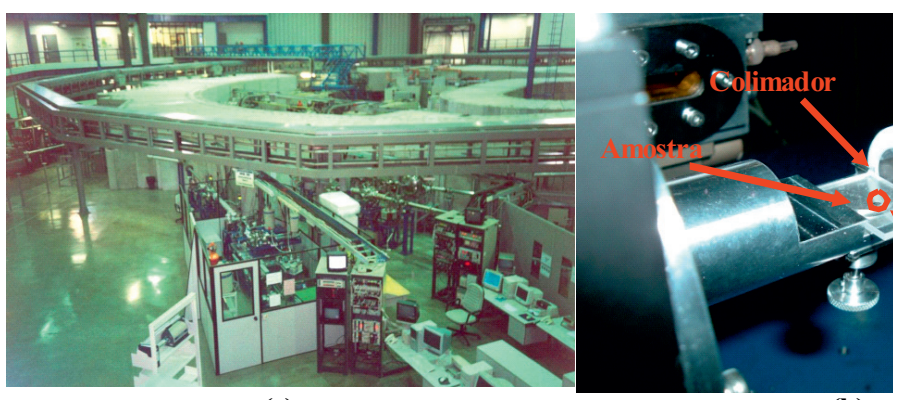

(a)

(b)

Figura 6 - Vista geral da estação experimental DO9B-XRF do LNLS (a) e arranjo experimental da SR-TXRF (b).

O arranjo experimental permite a rotação e a translação da amostra de forma a obter a condição para a reflexão total do feixe incidente sobre a amostra que está alocada numa placa retangular de lucite (Perspex) fixada no porta-amostra, permitindo a medida dos elementos contidos na amostra. A Figura $6 \mathrm{~b}$ mostra em detalhe a amostra depositada sobre o refletor e o detector com o colimador (PÉREZ et al., 1999)

\section{RESULTADOS E DISCUSSÃO}

\subsection{Análise quantitativa do PM10}

Na tabelas 1, 2 e 3 são apresentadas as concentrações do material particulado, nas duas frações, grossa e fina para os 3 postos de monitoramento. As concentrações nas frações grossa e fina foram determinadas pela análise gravimétrica enquanto que a concentração das partículas totais em suspensão (PM10) foi obtida pela soma das duas frações.

Tabela 1 - Concentrações das frações fina, grossa e PM10 ( $\mu$ g.m-3) no posto de Barão Geraldo.

\begin{tabular}{cccc}
\hline Data da Coleta & Fração Fina & Fração Grossa & PM $_{\mathbf{1 0}}$ \\
\hline $18 / 10 / 2005$ & 13,17 & 60,56 & 73,73 \\
$25 / 10 / 2005$ & 20,03 & 72,62 & 92,65 \\
$01 / 11 / 2005$ & 4,99 & 24,99 & 29,98 \\
$08 / 11 / 2005$ & 2,71 & 19,65 & 22,36 \\
$15 / 11 / 2005$ & 21,30 & 74,57 & 95,87 \\
$22 / 11 / 2005$ & 2,35 & 34,07 & 36,42 \\
$29 / 11 / 2005$ & 4,21 & 31,15 & 35,36 \\
$06 / 12 / 2005$ & 12,63 & 58,10 & 70,73 \\
$13 / 12 / 2005$ & 10,99 & 40,29 & 51,28 \\
$20 / 12 / 2005$ & 7,62 & 55,89 & 63,51 \\
$28 / 12 / 2005$ & 5,80 & 101,49 & 107,29 \\
$06 / 01 / 2006$ & 21,21 & 65,98 & 87,19 \\
$14 / 01 / 2006$ & 11,69 & 78,89 & 90,58 \\
$21 / 01 / 2006$ & 26,40 & 44,68 & 71,08 \\
$28 / 01 / 2006$ & 28,71 & 66,99 & 95,70 \\
$04 / 02 / 2006$ & 6,17 & 71,96 & 78,13 \\
$11 / 02 / 2006$ & 13,59 & 78,85 & 92,44 \\
$18 / 02 / 2006$ & 11,27 & 84,50 & 95,77 \\
$25 / 02 / 2006$ & 8,76 & 70,12 & 78,88 \\
$07 / 03 / 2006$ & 1,73 & 37,97 & 39,70 \\
$14 / 03 / 2006$ & 24,29 & 43,18 & 67,47 \\
\hline
\end{tabular}

O Padrão de Qualidade do Ar estabelecido pela CETESB relata que o valor máximo de PM10 para que a qualidade do ar seja 
considerada regular é de $150 \mu \mathrm{g} . \mathrm{m}$-3 para uma amostragem de 24 horas. Pode-ser verificar pela figura 7 que na maioria dos postos os valores foram inferiores ao valor de $150 \mu \mathrm{g} . \mathrm{m}-3$, porém para as $3^{\mathrm{a}}, 5^{\mathrm{a}}, 7^{\mathrm{a}}$ e $10^{\mathrm{a}}$ semanas de coleta no Posto do Centro da cidade de Campinas

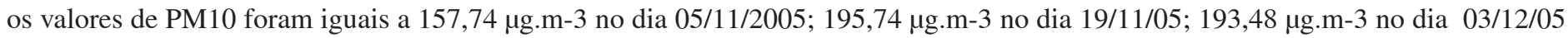
e 171,57 $\mu$ g.m-3 no dia 24/12/2005. Para o Posto de Paulínia o valor de referência foi ultrapassado apenas na $3^{\mathrm{a}}$ semana de coleta, cujo valor foi igual a $218,50 \mu \mathrm{g} \cdot \mathrm{m}-3$ no dia $03 / 11 / 2005$.

Tabela 2 - Concentrações das frações fina, grossa e PM10 ( $\mu$ g.m-3) no posto de Paulínia.

\begin{tabular}{cccc}
\hline Data de Coleta & Fração Fina & Fração Grossa & PM $_{\mathbf{1 0}}$ \\
\hline $20 / 10 / 2005$ & 5,27 & 21,08 & 26,35 \\
$27 / 10 / 2005$ & 16,79 & 63,79 & 80,58 \\
$03 / 11 / 2005$ & 81,94 & 136,56 & $\mathbf{2 1 8 , 5 0 *}$ \\
$10 / 11 / 2005$ & 4,09 & 23,77 & 27,86 \\
$17 / 11 / 2005$ & 18,45 & 57,41 & 75,86 \\
$24 / 11 / 2005$ & 4,03 & 39,01 & 43,04 \\
$01 / 12 / 2005$ & 5,99 & 21,39 & 27,38 \\
$08 / 12 / 2005$ & 12,57 & 50,28 & 62,85 \\
$15 / 12 / 2005$ & 9,89 & 27,19 & 37,08 \\
$22 / 12 / 2005$ & 5,09 & 55,96 & 61,05 \\
$30 / 12 / 2005$ & 7,29 & 46,16 & 53,45 \\
$10 / 01 / 2006$ & 7,30 & 51,09 & 58,39 \\
$17 / 01 / 2006$ & 25,07 & 39,17 & 64,24 \\
$24 / 01 / 2006$ & 30,75 & 46,12 & 76,87 \\
$31 / 01 / 2006$ & 2,59 & 54,50 & 57,09 \\
$07 / 02 / 2006$ & 8,02 & 61,51 & 69,53 \\
$14 / 02 / 2006$ & 7,17 & 31,06 & 38,23 \\
$21 / 02 / 2006$ & 18,48 & 46,21 & 64,69 \\
$02 / 03 / 2006$ & 10,51 & 63,05 & 73,56 \\
$09 / 03 / 2006$ & 4,19 & 46,07 & 50,26 \\
$16 / 03 / 2006$ & 21,23 & 89,15 & 110,38 \\
\hline
\end{tabular}

* Valor acima do considerado como regular para a qualidade do ar segundo a CETESB.

Tabela 3 - Concentrações das frações fina, grossa e PM10 ( $\mu$ g.m-3) no posto do Centro da cidade de Campinas.

\begin{tabular}{cccc}
\hline Data da Coleta & Fração Fina & Fração Grossa & PM $_{\mathbf{1 0}}$ \\
\hline $22 / 10 / 2005$ & 16,95 & 46,62 & 63.57 \\
$29 / 10 / 2005$ & 18,20 & 103,20 & 121,40 \\
$05 / 11 / 2005$ & 15,39 & 142,35 & $\mathbf{1 5 7 , 7 4 *}$ \\
$12 / 11 / 2005$ & 15,25 & 121,98 & 137,23 \\
$19 / 11 / 2005$ & 36,42 & 159,32 & $\mathbf{1 9 5 , 7 4 *}$ \\
$26 / 11 / 2005$ & 12,37 & 107,18 & 119,55 \\
$03 / 12 / 2005$ & 21,50 & 171,98 & $\mathbf{1 9 3 , 4 8 *}$ \\
$10 / 12 / 2005$ & 8,96 & 138,94 & 147,90 \\
$17 / 12 / 2005$ & 18,99 & 106,37 & 125,36 \\
$24 / 12 / 2005$ & 27,93 & 143,64 & $\mathbf{1 7 1 , 5 7}$ \\
$04 / 01 / 2006$ & 34,54 & 66,62 & 101,16 \\
$12 / 01 / 2006$ & 27,73 & 104,76 & 132,49 \\
$19 / 01 / 2006$ & 15,82 & 90,95 & 106,77 \\
$26 / 01 / 2006$ & 18,83 & 69,95 & 88,78 \\
$02 / 02 / 2006$ & 16,05 & 51,36 & 67,41 \\
$09 / 02 / 2006$ & 11,13 & 75,72 & 86,85 \\
$16 / 02 / 2006$ & 9,98 & 97,31 & 107,29 \\
$23 / 02 / 2006$ & 18,50 & 60,79 & 79,29 \\
$04 / 03 / 2006$ & 23,00 & 103,51 & 126,51 \\
$11 / 03 / 2006$ & 15,77 & 89,37 & 105,14 \\
$18 / 03 / 2006$ & 17,39 & 89,42 & 106,81 \\
\hline * Valor acima do considerado & &
\end{tabular}

* Valor acima do considerado como regular para a qualidade do ar segundo a CETESB.

No posto de coleta montado na FEAGRI no distrito de Barão Geraldo os valores obtidos não ultrapassaram o valor de referência estabelecido pela CETESB para uma qualidade do ar considerada como regular.
A Figura 7 mostra a variação das partículas totais em suspensão (PM10) nos postos de coleta durante as 21 semanas de monitoramento. 


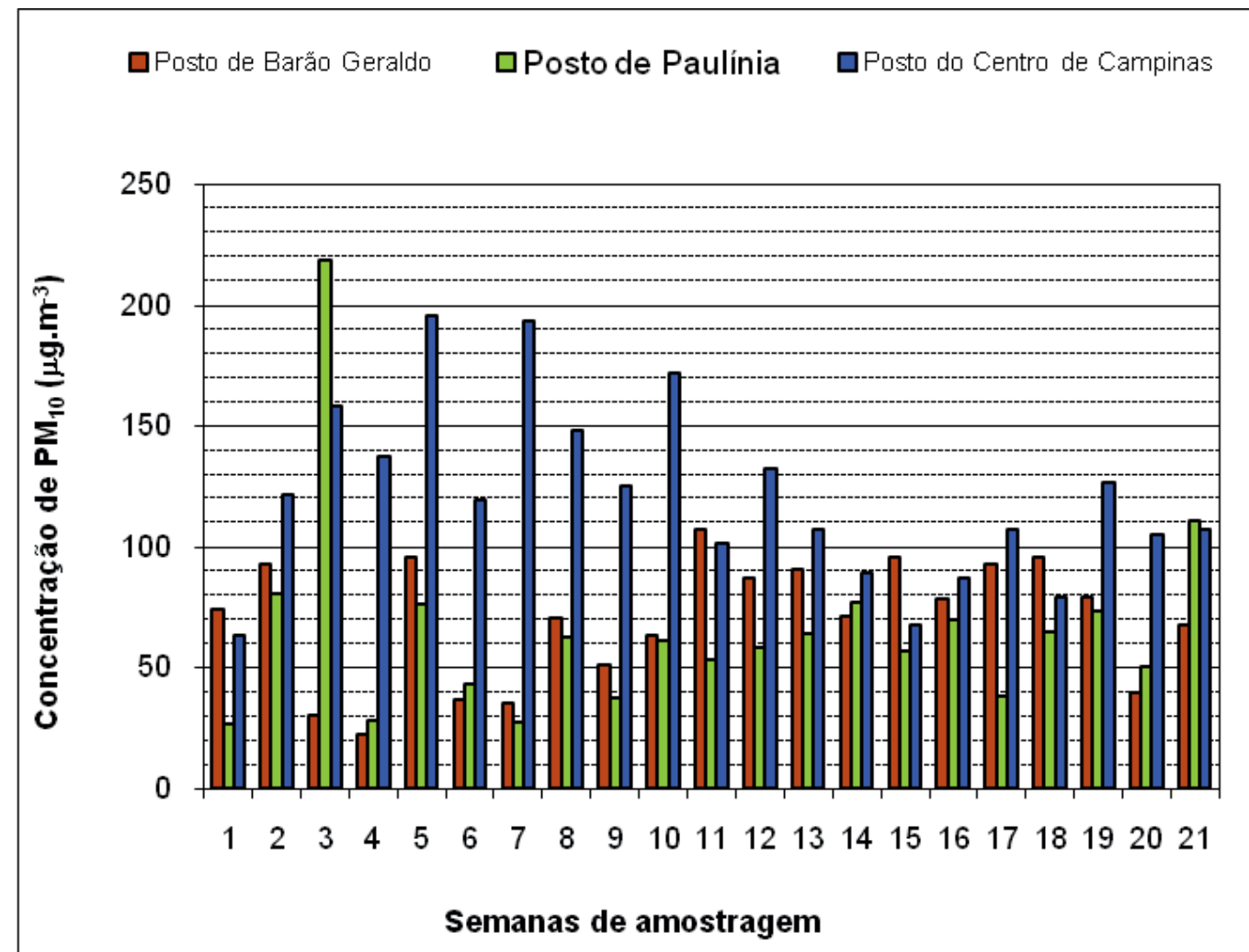

Figura 7 - Concentração ( $\mu g . m-3)$ do PM10 nos três postos de coleta durante o período de monitoramento.

Comparando os dados dos postos do Centro de Campinas e de Barão Geraldo com os valores obtidos por MATSUMOTO (2001) para essas duas localidades, podemos verificar que para o posto de Barão Geraldo a concentração de PM10 ficou por volta de $90 \mu \mathrm{g} . \mathrm{m}-3$, valor próximo aos obtidos por MATSUMOTO (70 $\mu \mathrm{g} . \mathrm{m}-3)$ durante o período de verão de 1999-2000.

Porém, para o posto do Centro de Campinas, neste trabalho os valores obtidos para o período de verão $(100 \mu \mathrm{g} . \mathrm{m}-3)$ foram bem superiores aos encontrados por MATSUMOTO (2001) no período de 1999-2000 (60 $\mu \mathrm{g} . \mathrm{m}-3)$. Isto mostra que a quantidade de partículas totais em suspensão (PM10) vem aumentando na região central da cidade de Campinas nos últimos anos.

Como não foi possível coletar dados durante o período do in-

Tabela 4 - Concentrações mínima, média e máxima ( $\mu$ g.m-3) do particulado grosso e fino, no posto de Barão Geraldo.

\begin{tabular}{ccccccc} 
& \multicolumn{7}{c}{ Concentração $\left(\boldsymbol{\mu g} . \mathbf{m}^{-3}\right.$ ) } \\
\cline { 2 - 7 } & \multicolumn{5}{c}{ Fração Grossa } & Mraçáo Fina \\
\hline Elemento & Mínima & Máxima & Média & Mínima & Máxima & Média \\
$\mathrm{Al}$ & 0,9237 & 11,1768 & 3,8594 & 0,0550 & 1,0363 & 0,3578 \\
$\mathrm{Si}$ & 0,4238 & 7,1198 & 2,9607 & 0,0126 & 0,2690 & 0,1004 \\
$\mathrm{P}$ & 0,4341 & 2,4394 & 1,3042 & 0,0252 & 0,2623 & 0,1068 \\
$\mathrm{~S}$ & 0,4877 & 4,9013 & 1,6599 & 0,0316 & 0,7859 & 0,2417 \\
$\mathrm{Cl}$ & 0,4744 & 4,4730 & 2,3816 & 0,0434 & 0,4386 & 0,2283 \\
$\mathrm{~K}$ & 0,0555 & 0,8912 & 0,2764 & 0,0404 & 0,2669 & 0,1146 \\
$\mathrm{Ca}$ & 0,1824 & 2,2821 & 0,7573 & 0,0954 & 0,7667 & 0,2720 \\
$\mathrm{Ti}$ & 0,0033 & 0,1398 & 0,0273 & 0,0007 & 0,0190 & 0,0056 \\
$\mathrm{~V}$ & 0,0034 & 0,0466 & 0,0168 & 0,0008 & 0,0203 & 0,0073 \\
$\mathrm{Cr}$ & 0,0580 & 1,7759 & 0,7014 & 0,0207 & 0,5819 & 0,1935 \\
$\mathrm{Mn}$ & 0,0030 & 0,1094 & 0,0409 & 0,0023 & 0,0713 & 0,0131 \\
$\mathrm{Fe}$ & 0,9620 & 11,8408 & 3,8041 & 0,3423 & 2,6441 & 1,2237 \\
$\mathrm{Co}$ & 0,0037 & 0,0372 & 0,0166 & 0,0015 & 0,0231 & 0,0082 \\
$\mathrm{Ni}$ & 0,0034 & 0,3608 & 0,0864 & 0,0019 & 0,0616 & 0,0210 \\
$\mathrm{Cu}$ & 0,0088 & 0,1979 & 0,0537 & 0,0044 & 0,0335 & 0,0117 \\
$\mathrm{Zn}$ & 0,0627 & 0,5090 & 0,2902 & 0,0622 & 0,3887 & 0,2146 \\
$\mathrm{Se}$ & 0,0031 & 0,0232 & 0,0124 & 0,0023 & 0,0139 & 0,0055 \\
$\mathrm{Br}$ & 0,0033 & 0,1665 & 0,0454 & 0,0028 & 0,0245 & 0,0100 \\
$\mathrm{~Pb}$ & 0,0065 & 0,1852 & 0,0505 & 0,0059 & 0,0578 & 0,0224 \\
\hline
\end{tabular}

verno, caracterizado por uma maior estiagem, não se pôde verificar a qualidade do ar para esse período. Porém, pelos valores obtidos para o período do verão; é plausível esperar uma piora na qualidade do ar atmosférico para a região de Campinas para o período inverno, pois neste período o material particulado tende a ficar disperso na atmosfera por mais tempo, prejudicando a qualidade do ar.

3.2. Análise das concentrações dos elementos contidos no material particulado

Através da análise quantitativa por SR-TXRF das frações fina e grossa do material particulado, realizada no Laboratório Nacional de Luz Síncrotron, foram detectados 19 elementos químicos (Al; Si; P; S; Cl; K; Ca; Ti; V; Cr; Mn; Fe; Co; Ni; Cu; Zn; Se; $\mathrm{Br}$ e $\mathrm{Pb})$.

Tabela 5 - Concentrações mínima, média e máxima ( $\mu$ g.m-3) do particulado grosso e fino, no posto de Paulínia.

\begin{tabular}{ccccccc} 
& \multicolumn{6}{c}{ Concentração $\left(\boldsymbol{\mu g . m} \mathbf{m}^{-3}\right)$} \\
\cline { 2 - 7 } & \multicolumn{7}{c}{ Fração Grossa } & Mração Fina & \\
\cline { 2 - 7 } Elemento & Mínima & Máxima & Média & Mína & Máxima & Média \\
\hline $\mathrm{Al}$ & 0,3965 & 22,6856 & 4,4851 & 0,1682 & 2,9905 & 0,7322 \\
$\mathrm{Si}$ & 0,3866 & 9,7879 & 2,6599 & 0,0564 & 1,8429 & 0,4335 \\
$\mathrm{P}$ & 0,1274 & 6,7102 & 1,0394 & 0,0597 & 1,4362 & 0,3259 \\
$\mathrm{~S}$ & 0,1510 & 6,4228 & 0,9837 & 0,0417 & 1,6665 & 0,3214 \\
$\mathrm{Cl}$ & 0,6046 & 27,3956 & 3,6602 & 0,0741 & 2,8208 & 0,7536 \\
$\mathrm{~K}$ & 0,0888 & 2,8626 & 0,4163 & 0,0163 & 0,5337 & 0,1449 \\
$\mathrm{Ca}$ & 0,2032 & 9,7509 & 1,4488 & 0,0945 & 2,0302 & 0,4846 \\
$\mathrm{Ti}$ & 0,0095 & 0,2151 & 0,0382 & 0,0008 & 0,0156 & 0,0060 \\
$\mathrm{~V}$ & 0,0034 & 0,1517 & 0,0316 & 0,0005 & 0,0278 & 0,0072 \\
$\mathrm{Cr}$ & 0,0544 & 1,2218 & 0,3725 & 0,0225 & 0,6337 & 0,1519 \\
$\mathrm{Mn}$ & 0,0100 & 0,0977 & 0,0404 & 0,0025 & 0,0721 & 0,0181 \\
$\mathrm{Fe}$ & 0,2768 & 7,9613 & 2,8132 & 0,1946 & 3,3757 & 1,2650 \\
$\mathrm{Co}$ & 0,0014 & 0,0388 & 0,0156 & 0,0008 & 0,0214 & 0,0074 \\
$\mathrm{Ni}$ & 0,0069 & 0,2243 & 0,0516 & 0,0024 & 0,0194 & 0,0084 \\
$\mathrm{Cu}$ & 0,0078 & 0,3377 & 0,0531 & 0,0029 & 0,0449 & 0,0176 \\
$\mathrm{Zn}$ & 0,0986 & 2,4986 & 0,4294 & 0,0334 & 1,0347 & 0,2587 \\
$\mathrm{Se}$ & 0,0021 & 0,0323 & 0,0090 & 0,0010 & 0,0113 & 0,0039 \\
$\mathrm{Br}$ & 0,0114 & 0,2084 & 0,0418 & 0,0017 & 0,0948 & 0,0171 \\
$\mathrm{~Pb}$ & 0,0137 & 1,3661 & 0,1680 & 0,0093 & 0,1671 & 0,0449 \\
\hline
\end{tabular}


Em todos os postos de coleta, as amostras foram feitas em triplicata e as medidas realizadas por 100 segundos.

As concentrações mínima, média e máxima obtidas por SR-TXRF para o particulado grosso e fino, são apresentadas nas tabelas 4 , 5 e 6 para os Postos de Barão Geraldo, Paulínia e Centro da Cidade de Campinas, respectivamente.

Tabela 6 - Concentrações mínima, média e máxima ( $\mu \mathrm{g} . \mathrm{m}-3)$ do particulado grosso e fino, no posto do Centro de Campinas.

\begin{tabular}{|c|c|c|c|c|c|c|}
\hline \multirow[b]{3}{*}{ Elemento } & \multicolumn{6}{|c|}{ Concentração $\left(\mu \mathrm{g} \cdot \mathrm{m}^{-3}\right)$} \\
\hline & \multicolumn{3}{|c|}{ Fracão Grossa } & \multicolumn{3}{|c|}{ Fração Fina } \\
\hline & Mínima & Máxima & Média & Mínima & Máxima & Média \\
\hline $\mathrm{Al}$ & 0,7894 & 11,7558 & 3,6557 & 0,1809 & 1,7606 & 0,6634 \\
\hline $\mathrm{Si}$ & 0,2054 & 5,9214 & 1,5773 & 0,0808 & 0,5602 & 0,2583 \\
\hline $\mathrm{P}$ & 0,2821 & 3,5059 & 1,2430 & 0,0513 & 0,5408 & 0,2291 \\
\hline $\mathrm{S}$ & 0,3375 & 3,3120 & 1,2553 & 0,1547 & 1,2161 & 0,5063 \\
\hline $\mathrm{Cl}$ & 1,6924 & 11,8853 & 4,8465 & 0,2182 & 2,9321 & 0,9846 \\
\hline $\mathrm{K}$ & 0,1317 & 1,2940 & 0,4074 & 0,0852 & 0,3172 & 0,1868 \\
\hline $\mathrm{Ca}$ & 0,7012 & 5,6105 & 1,6439 & 0,1963 & 1,3126 & 0,6844 \\
\hline $\mathrm{Ti}$ & 0,0079 & 0,1351 & 0,0354 & 0,0027 & 0,0401 & 0,0103 \\
\hline $\mathrm{V}$ & 0,0119 & 0,0827 & 0,0342 & 0,0024 & 0,0155 & 0,0065 \\
\hline $\mathrm{Cr}$ & 0,1973 & 4,3951 & 1,2064 & 0,1284 & 0,9966 & 0,3267 \\
\hline $\mathrm{Mn}$ & 0,0111 & 0,1614 & 0,0424 & 0,0038 & 0,0462 & 0,0130 \\
\hline $\mathrm{Fe}$ & 1,5149 & 10,5567 & 3,9418 & 0,4997 & 3,1450 & 1,3128 \\
\hline $\mathrm{Co}$ & 0,0053 & 0.0455 & 0,0214 & 0,0015 & 0,0168 & 0,0074 \\
\hline $\mathrm{Ni}$ & 0.0122 & 0.6304 & 0,1265 & 0.0034 & 0.0331 & 0.0157 \\
\hline $\mathrm{Cu}$ & 0,0291 & 0,1678 & 0,0583 & 0,0035 & 0,0392 & 0,0150 \\
\hline $\mathrm{Zn}$ & 0,2122 & 0,9720 & 0,4858 & 0,2026 & 0,6209 & 0,3765 \\
\hline $\mathrm{Se}$ & 0,0062 & 0,0320 & 0,0180 & 0,0028 & 0,0282 & 0,0112 \\
\hline $\mathrm{Br}$ & 0,0245 & 0,1587 & 0,0695 & 0,0040 & 0,0456 & 0,0209 \\
\hline $\mathrm{Pb}$ & 0,0457 & 0,4743 & 0,1879 & 0,0221 & 0,2027 & 0,0605 \\
\hline
\end{tabular}

$\mathrm{Na}$ fração grossa do material particulado os elementos predominantes para os três postos de coleta são: $\mathrm{Al} ; \mathrm{Si} ; \mathrm{P} ; \mathrm{Cl} ; \mathrm{Ca}$ e Fe.

$\mathrm{O}$ elemento $\mathrm{Pb}$ tem predominância nos postos de Paulínia e do Centro de Campinas, como esperado, visto que nestes locais, a emissão industrial e veicular, deve ser superior ao distrito de Barão Geraldo. Este mesmo comportamento foi observado para o V. O elemento Fe está presente igualmente nos três postos de coleta, indicando a associação deste elemento com a poeira do solo.

$\mathrm{Na}$ fração fina do material particulado os elementos Al; Si; P; S; $\mathrm{Cl}$; K; Ca; Cr; Fe e Zn são os que apresentam maior contribuição em massa, para os três postos de coleta. E os elementos que contribuem com uma menor relação na fração fina são: Ti; V; Mn; $\mathrm{Co} ; \mathrm{Ni} ; \mathrm{Cu} ; \mathrm{Se} ; \mathrm{Br}$ e $\mathrm{Pb}$.

Assim como ocorreu para o particulado grosso, a relação percentual do Fe contida no particulado fino para o posto de Barão
Geraldo foi maior que os demais postos. Devemos lembrar que este posto localiza-se na estação meteorológica do CEPAGRI, numa região de solo Latossolo roxo, o qual apresenta uma concentração elevada de Fe. Portanto, é muito provável que a alta concentração de $\mathrm{Fe}$ encontrada na fração fina esteja correlacionada com a re-suspensão da poeira do solo nesta localidade.

Quanto ao elemento $\mathrm{Pb}$, podemos verificar que tanto na fração fina quanto na grossa os valores percentuais foram maiores nos postos de Paulínia e no Centro de Campinas, indicando uma associação deste elemento à emissão veicular.

As Tabelas 7 e 8 apresentam uma comparação dos valores obtidos neste trabalho para a fração grossa e fina, respectivamente com dados da cidade de Philadelphia (E.U.A.) fornecidos pela USEPA e ainda com os dados apresentados por MATSUMOTO (2001).

Tabela 7 - Comparação dos valores obtidos para a fração grossa do material particulado deste trabalho com dados da cidade de Philadelphia e os obtidos por MATSUMOTO (2001).

\begin{tabular}{|c|c|c|c|c|c|c|}
\hline \multirow[b]{3}{*}{ Elemento } & \multicolumn{6}{|c|}{ Concentração $\left(\right.$ ng.m $\left.{ }^{-3}\right)$ - Fração Grossa } \\
\hline & \multicolumn{3}{|c|}{ Este trabalho } & \multicolumn{2}{|c|}{ MATSUMOTO (2001) } & \multirow[b]{2}{*}{ Philadelphia } \\
\hline & Barão Geraldo & Paulínia & Campinas & Barão Geraldo & Campinas & \\
\hline $\mathrm{Al}$ & 3859 & 4485 & 3656 & 207 & 371 & 325 \\
\hline $\mathrm{Si}$ & 2961 & 2659 & 1577 & 542 & 1041 & 933 \\
\hline $\mathrm{P}$ & 1304 & 1039 & 1243 & --- & 28 & 28 \\
\hline $\mathrm{S}$ & 1660 & 984 & 1255 & 53 & 316 & 38 \\
\hline $\mathrm{Cl}$ & 2382 & 3660 & 4847 & --- & --- & 47 \\
\hline $\mathrm{K}$ & 276 & 416 & 407 & 87 & 214 & 100 \\
\hline $\mathrm{Ca}$ & 757 & 1449 & 1644 & 181 & 849 & 421 \\
\hline $\mathrm{Ti}$ & 27 & 38 & 35 & 32 & 106 & 30 \\
\hline V & 17 & 32 & 34 & 9 & 8 & 3 \\
\hline $\mathrm{Cr}$ & 701 & 373 & 1206 & 5 & 10 & 1 \\
\hline $\mathrm{Mn}$ & 41 & 40 & 42 & 5 & 14 & 6 \\
\hline $\mathrm{Fe}$ & 3804 & 2813 & 3942 & 485 & 905 & 352 \\
\hline $\mathrm{Co}$ & 17 & 16 & 21 & 1 & 3 & --- \\
\hline $\mathrm{Ni}$ & 86 & 52 & 127 & 1 & 5 & 2 \\
\hline $\mathrm{Cu}$ & 54 & 53 & 58 & 5 & 13 & 14 \\
\hline $\mathrm{Zn}$ & 290 & 429 & 486 & 27 & 78 & 52 \\
\hline $\mathrm{Se}$ & 12 & 9 & 18 & --- & 1 & --- \\
\hline $\mathrm{Br}$ & 45 & 42 & 70 & --- & 2 & 3 \\
\hline $\mathrm{Pb}$ & 51 & 168 & 188 & 2 & 4 & 13 \\
\hline
\end{tabular}


artigos técnicos

Comparando os valores médios para os três postos de monitoramento com os da cidade de Philadelphia e os obtidos por MATSUMOTO (2001) podemos verificar que as concentrações de Al; $\mathrm{Si}$; P; S; Cl; $\mathrm{Cr}, \mathrm{Fe}, \mathrm{Ni}, \mathrm{Cu}, \mathrm{Zn}$ e $\mathrm{Pb}$ são superiores ao da cidade de Philadelphia e também superiores ao encontrados por MATSUMOTO. Para os elementos $\mathrm{K}, \mathrm{Ca}$, Ti e os valores obtidos neste trabalho estão próximos dos valores da cidade de Philadelphia e dos encontrados por MATSUMOTO.

Podemos observar pela tabela 8 que os valores médios encontrados nos três postos de coleta para a fração fina do material particulado estão na mesma faixa dos obtidos para a cidade de Philadelphia para os elementos $\mathrm{Si}$; Ti; V; Ni; $\mathrm{Se} ; \mathrm{Br}$ e $\mathrm{Pb}$. Para os elementos Al; P; Cl; K; Ca; Cr; $\mathrm{Mn}$, $\mathrm{Fe}, \mathrm{Ni}, \mathrm{Co}, \mathrm{Cu}$ e $\mathrm{Zn}$ os valores médios foram superiores aos valores da cidade de Philadelphia. Para o elemento S os valores médios em Philadelphia são bem superiores aos encontrados nos três postos de monitoramento.

Comparando-se os valores obtidos por MATSUMOTO (2001) e os determinados neste trabalho podemos observar que as concentrações de $\mathrm{Si}, \mathrm{S}, \mathrm{Ti}, \mathrm{V}$, e Mn são muito próximas, mas para os outros elementos as concentrações deste trabalho são superiores aos de MATSUMOTO, principalmente para os elementos $\mathrm{Al}, \mathrm{P}, \mathrm{Cr}, \mathrm{Fe}, \mathrm{Ni}, \mathrm{Zn}$ e $\mathrm{Pb}$.

Tabela 8 - Comparação dos valores obtidos para os três postos de monitoramento com os valores para a cidade de Philadelphia para a fração fina do material particulado.

\begin{tabular}{ccccccc}
\cline { 2 - 6 } & \multicolumn{5}{c}{ Concentração $\left(\right.$ ng.m $\left.^{-3}\right)$} & - Fração Fina \\
\cline { 2 - 5 } Este trabalho & \multicolumn{4}{c}{ MATSUMOTO (2001) } & \\
\cline { 2 - 5 } Elemento & Barão Geraldo & Paulínia & Campinas & Barão Geraldo & Campinas & Philadelphia \\
\hline $\mathrm{Al}$ & 358 & 732 & 663 & 81 & 174 & 4 \\
$\mathrm{Si}$ & 100 & 433 & 258 & 68 & 165 & 116 \\
$\mathrm{P}$ & 107 & 326 & 229 & --- & 27 & 9 \\
$\mathrm{~S}$ & 242 & 321 & 506 & 307 & 374 & 2100 \\
$\mathrm{Cl}$ & 228 & 754 & 985 & --- & --- & 5 \\
$\mathrm{~K}$ & 115 & 145 & 187 & 24 & 52 & 60 \\
$\mathrm{Ca}$ & 272 & 485 & 684 & 33 & 90 & 47 \\
$\mathrm{Ti}$ & 6 & 6 & 10 & 4 & 12 & 5 \\
$\mathrm{~V}$ & 7 & 7 & 7 & 2 & 6 & 9 \\
$\mathrm{Cr}$ & 193 & 152 & 327 & 3 & 19 & 1 \\
$\mathrm{Mn}$ & 13 & 18 & 13 & 2 & 4 & 3 \\
$\mathrm{Fe}$ & 1224 & 1265 & 1313 & 31 & 108 & 109 \\
$\mathrm{Co}$ & 8 & 7 & 7 & 1 & 1 & 1 \\
$\mathrm{Ni}$ & 21 & 8 & 16 & 1 & 3 & 7 \\
$\mathrm{Cu}$ & 12 & 18 & 15 & 2 & 5 & 5 \\
$\mathrm{Zn}$ & 215 & 259 & 376 & 17 & 33 & 37 \\
$\mathrm{Se}$ & 6 & 4 & 11 & 1 & 2 & 2 \\
$\mathrm{Br}$ & 10 & 17 & 21 & --- & 2, & 5 \\
$\mathrm{~Pb}$ & 22 & 45 & 61 & 4 & 5 & 18 \\
\hline
\end{tabular}

3.3. Contribuição das fontes de emissão no material particulado grosso

A partir da quantificação da concentração do material particulado grosso pode-se determinar a fração da concentração de massa associada a cada fator. As figuras 8 a 10 mostram as porcentagens de concentração de particulado grosso, associada a cada fonte emissora, em cada um dos três postos de coleta.

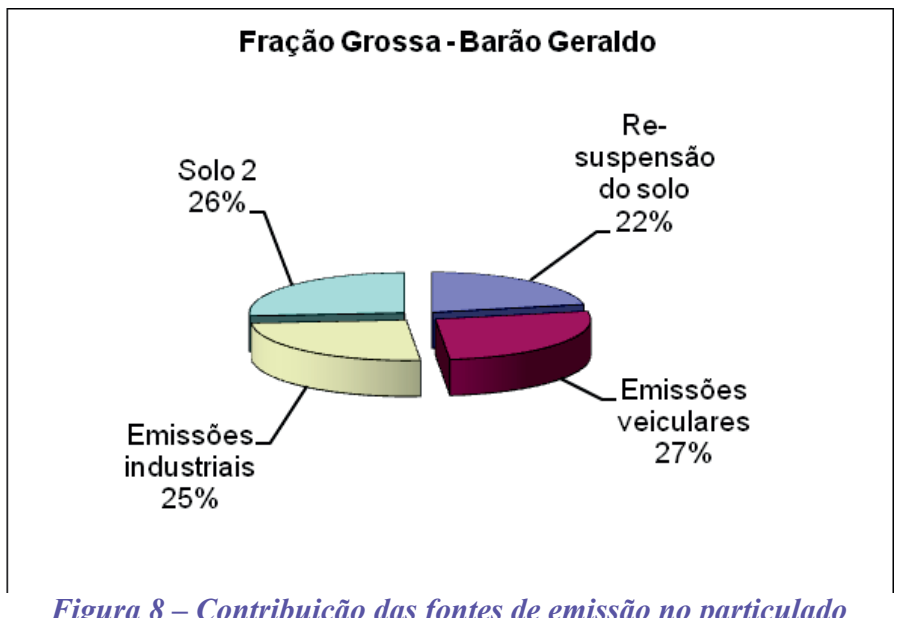

Figura 8 - Contribuição das fontes de emissão no particulado grosso para o posto de Barão Geraldo.

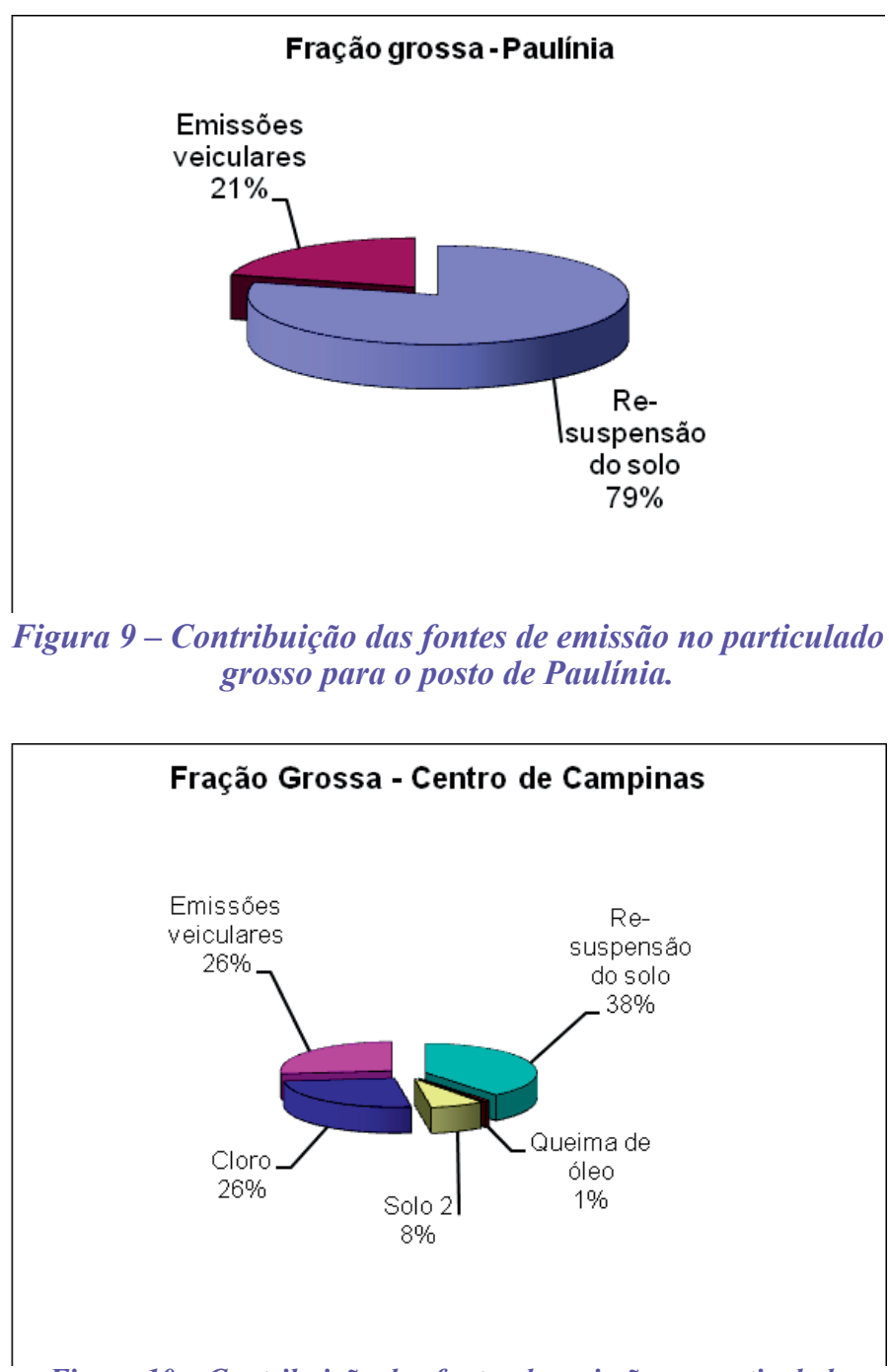

Figura 10 - Contribuição das fontes de emissão no particulado grosso para o posto do centro de Campinas.

Segundo CASTANHO (1999 apud MATSUMOTO, 2001) os elementos provenientes da re-suspensão de solo são: Al, $\mathrm{Si}, \mathrm{Ti}, \mathrm{Fe}, \mathrm{Ca}, \mathrm{V}$ e K. Para a emissão industrial os elementos que mais contribuem são: $\mathrm{Zn}, \mathrm{Ni}, \mathrm{Cr}, \mathrm{Mn}$ e S. Na emissão veicular os elementos com maior contribuição são: Co, $\mathrm{Pb}$ e $\mathrm{V}$.

A contribuição da poeira do solo foi responsável por 79\%, 


\section{artigos técnicos}

$48 \%$ e $46 \%$ do total da fração grossa para o posto de Paulínia, Barão Geraldo, e Centro de Campinas, respectivamente. O posto de Paulínia foi o que apresentou uma maior porcentagem da contribuição da poeira do solo, o que pode ser explicado pelo fato do posto de coleta estar localizado próximo a uma área com solo cultivado.

A contribuição da emissão veicular foi de $21 \%$ para o posto de Paulínia enquanto que para o posto do Centro de Campinas foi observado um valor de $27 \%$ para as emissões veiculares e $1 \%$ relacionado a queima de óleo combustível. Como descrito anteriormente o posto do centro de Campinas está localizado na Avenida Anchieta, a qual apresenta um grande fluxo veicular de automóveis e transporte coletivo.

Por outro lado no posto de Barão Geraldo foi verificado que a emissão veicular contribui com $27 \%$ na fração grossa do material particulado. As emissões industriais contribuíram com $25 \%$ no posto de Barão Geraldo e isto pode ser explicado pela proximidade deste posto do pólo petroquímico

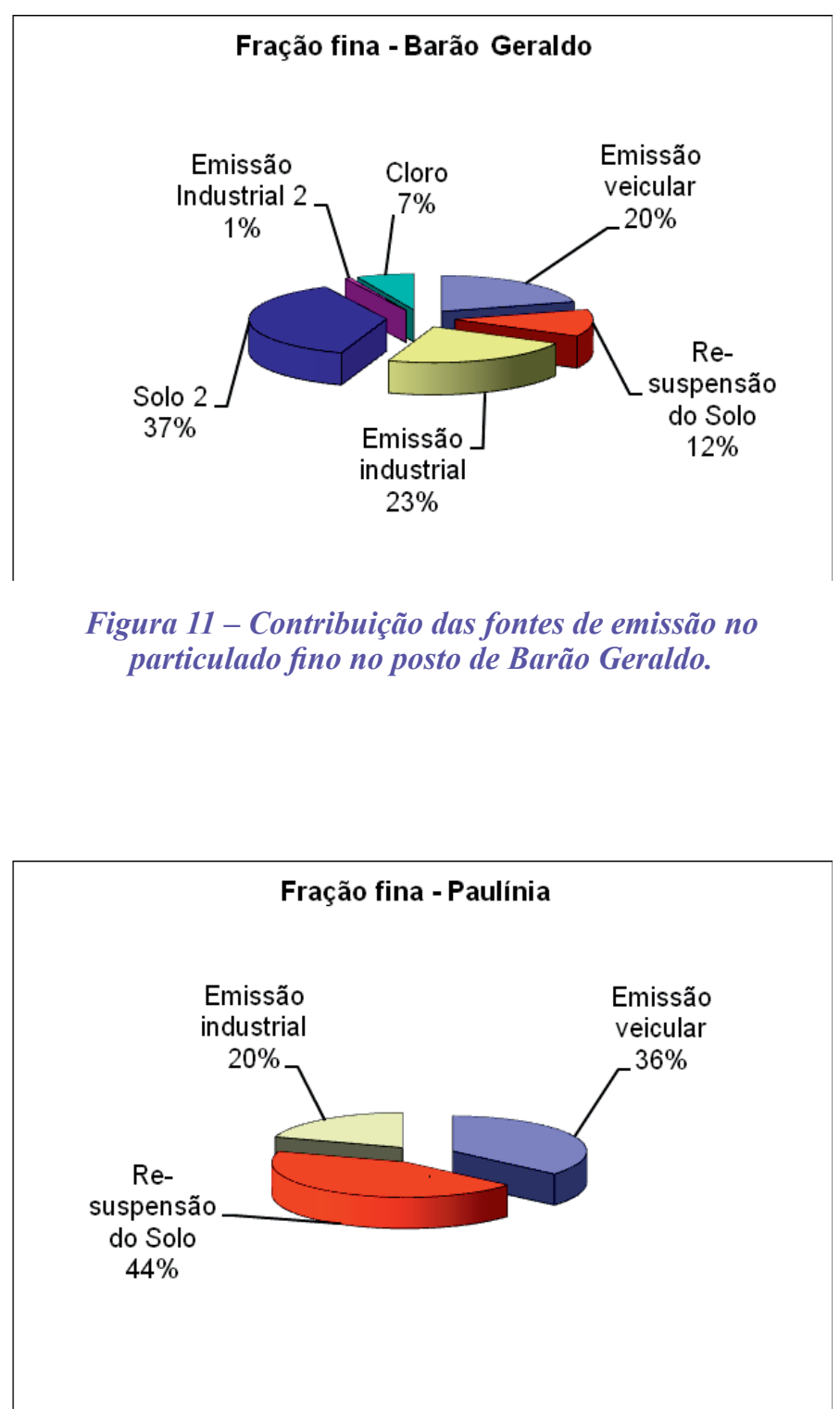

Figura 12 - Contribuição das fontes de emissão no particulado fino no posto de Paulínia. de Paulínia. Devido à predominância da direção dos ventos o material particulado é transportado para a região de Barão Geraldo.

\subsection{Contribuição das fontes de emissão no material particu- lado fino}

As contribuições das fontes de emissão no material particulado fino para os postos de monitoramento são apresentadas nas Figuras 11 à 13.

No material particulado fino coletado no Posto de Barão Geraldo a re-suspensão do solo contribui com $48 \%$, seguida da emissão industrial com $24 \%$ e da veicular com $21 \%$. No posto de Paulínia a poeira do solo é responsável por $44 \%$, a veicular por $36 \%$ e a industrial por $20 \%$. No Centro de Campinas a emissão veicular contribui com $31 \%$ valor próximo ao observado no posto de Paulínia e se devem ao fluxo veicular elevado nestas regiões. A poeira do solo contribui com $45 \%$ e é praticamente igual a dos outros postos de coleta. No que se refere a emissão industrial o posto do centro de Campinas contribui com apenas $7 \%$ enquanto que no posto de Barão esta porcentagem é de $24 \%$ e no de Paulínia $20 \%$.

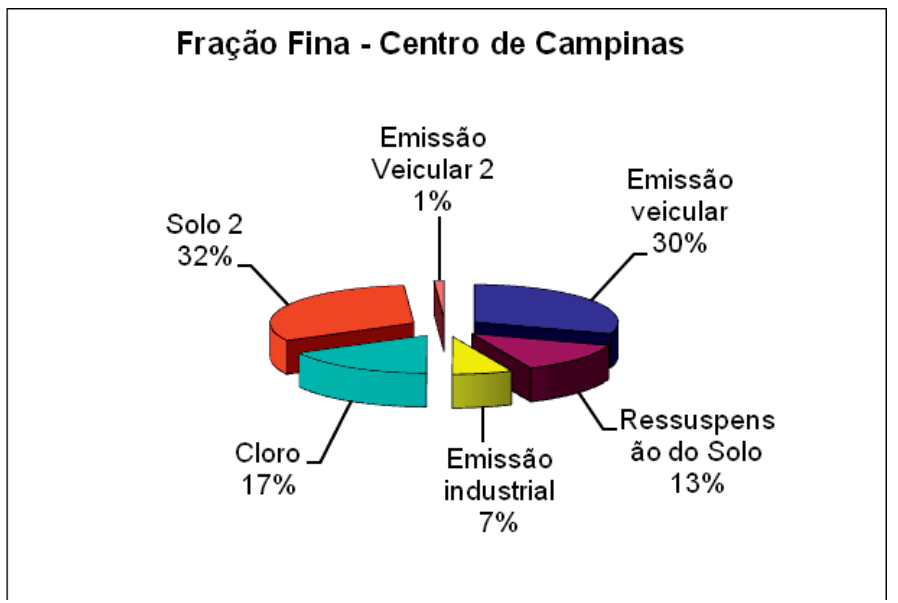

Figura 13 - Contribuição das fontes de emissão no particulado fino no posto do Centro de Campinas.

\subsection{Assinatura das fontes}

Os perfis das fontes deste trabalho são comparados com resultados de outros trabalhos em diferentes cidades. As razões entre as concentrações elementares e a massa de particulado inalável (PM10) definem o perfil da ressuspensão do solo enquanto que os perfis das demais fontes são apresentados pela razão entre as concentrações elementares e o particulado fino (PM2,5).

A figura 14 apresenta uma comparação do perfil de emissão veicular obtido neste trabalho com os obtidos por outros autores. 


\section{artigos técnicos}

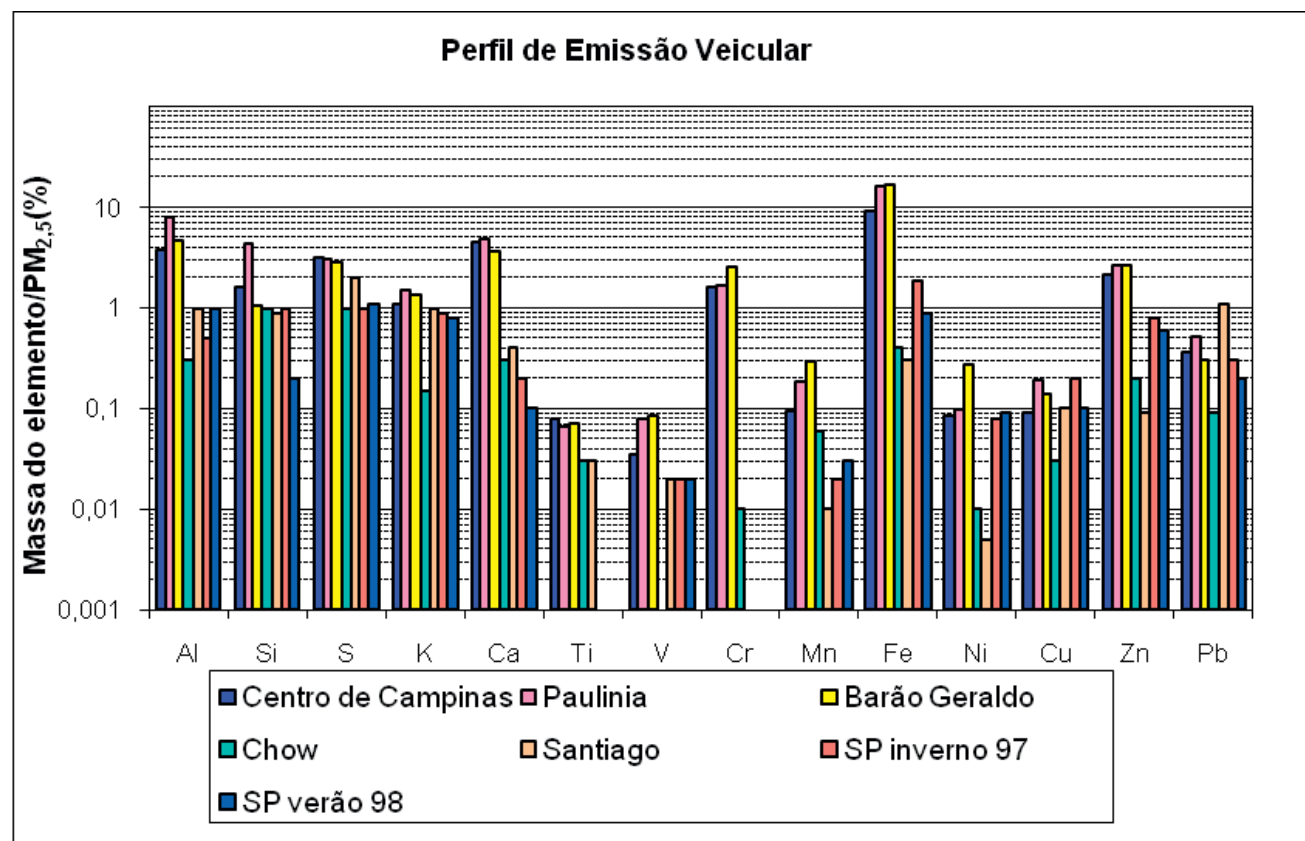

Figura 14 - Perfis de emissão veicular obtida para o Centro de Campinas, Barão Geraldo e Paulínia comparados com os obtidos para as cidades de Santiago do Chile (ARTAXO, 1999) e São Paulo (CASTANHO, 1999) e com a assinatura de veículos, diesel e gasolina, obtida por CHOW et al. (CHOW et al., 1994).

De forma geral os perfis de emissão veicular (Figura 14) são comparáveis aos obtidos para as cidades de Santiago do Chile e São Paulo, porém um pouco diferentes do perfil descrito por CHOW et al., 1994. Apenas para o elemento Ca e Fe podemos observar valores mais elevados que os obtidos pelos outros autores.

Os altos valores obtidos para $\mathrm{Pb}$ na cidade de Santiago eram esperados uma vez que o $\mathrm{Pb}$ ainda era usado como aditivo na gasolina. $\mathrm{O}$ perfil de emissão veicular apresenta ainda uma significativa concentração de $\mathrm{Zn}$ e $\mathrm{Pb}$ que são traçadores de emissão industrial.

A Figura 15 apresenta uma comparação do perfil de queima de óleo combustível obtido neste trabalho com os obtidos por outros autores e com o perfil fornecido pela EPA.

Como podemos observar existe uma boa concordância dos resultados obtidos neste trabalho quando comparados aos obtidos por outros autores e em diferentes localidades. Comparando os valores de $\mathrm{V}$ e $\mathrm{Ni}$ obtidos neste trabalho com a assinatura da EPA podemos notar uma discrepância, mas quando comparados aos valores obtidos para as cidades de Santiago e São Paulo podemos observar uma razoável concordância.

A Figura 16 apresenta uma comparação do perfil da poeira do solo obtido neste trabalho com os obtidos por outros autores.

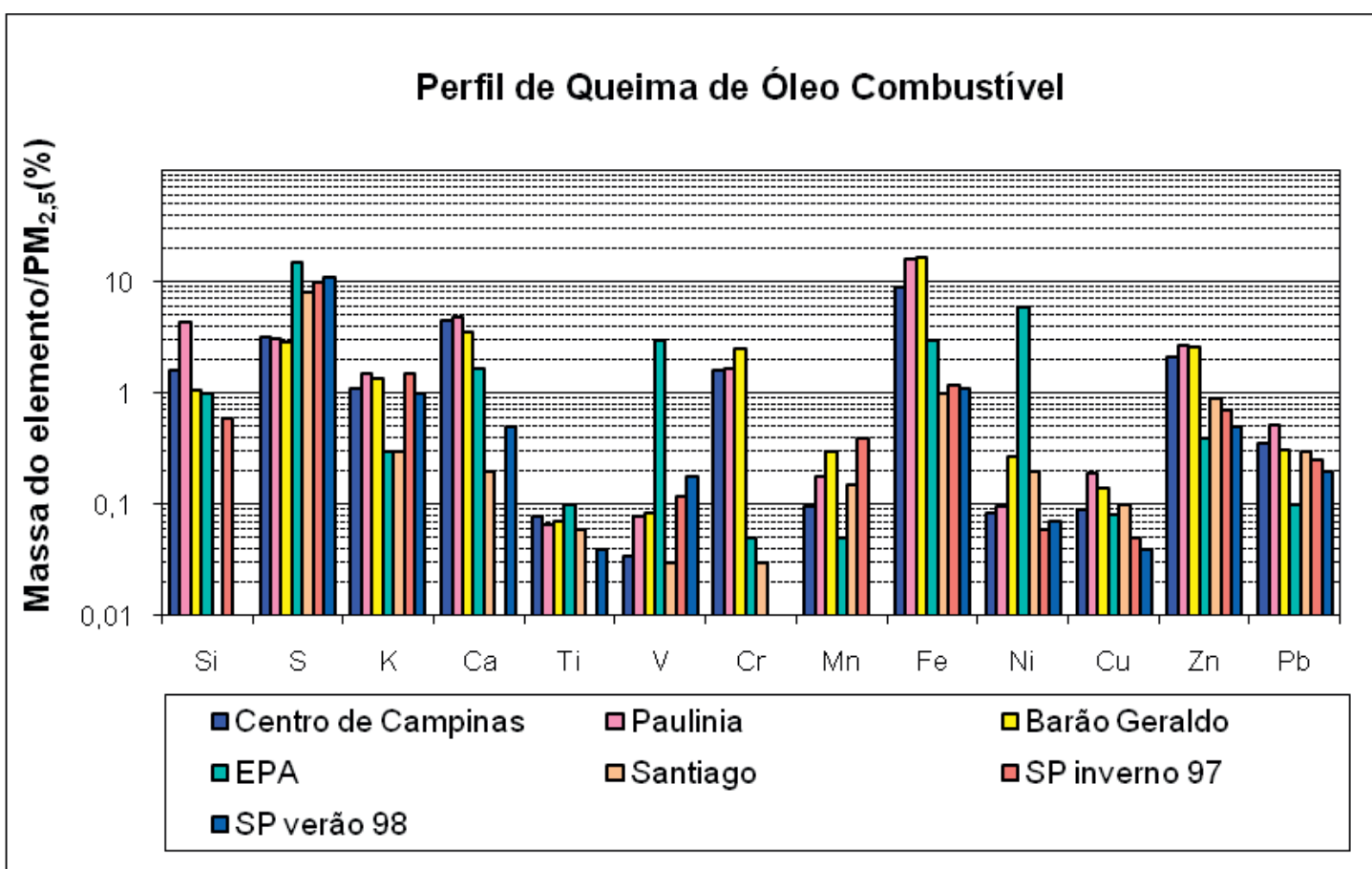

Figura 15 - Perfis de queima de óleo combustível obtida para o Centro de Campinas, Barão Geraldo e Paulínia comparados com os obtidos para as cidades de Santiago do Chile (ARTAXO, 1999) e São Paulo (CASTANHO, 1999) e com a assinatura de queima de óleo combustivel da EPA (EPA Source Profile Library, CMB). 


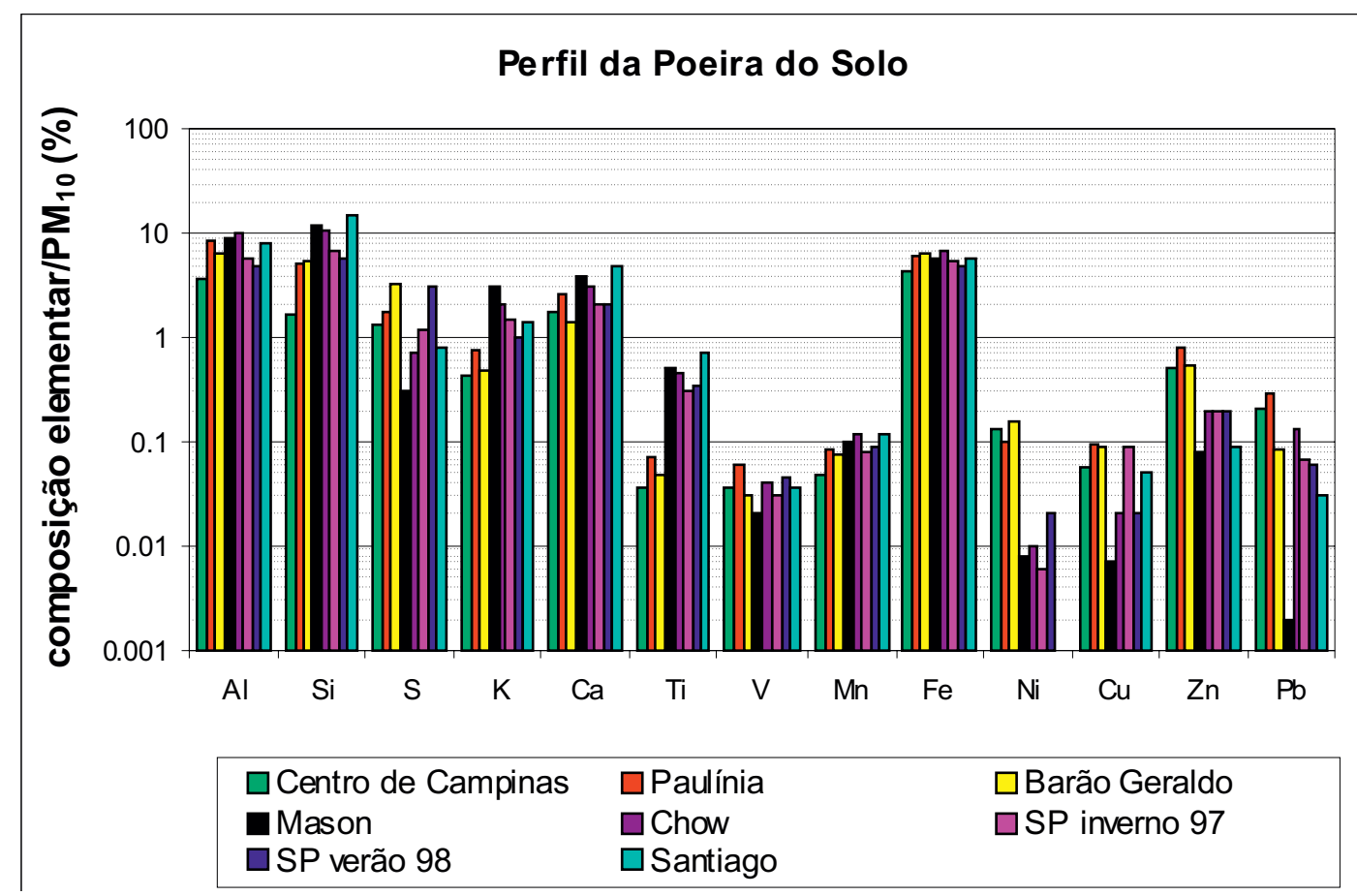

Figura 16 - Perfis de ressuspensão do solo obtidos para o Centro de Campinas, Barão Geraldo e Paulínia comparados com a assinatura de solo MASON (MASON, 1966), CHOW et al., (SEINFELD e PANDIS, 1998) e Santiago do Chile (ARTAXO, 1999) e São Paulo (CASTANHO, 1999).

Os perfis de ressuspensão do solo obtidos neste trabalho podem ser comparados com as assinaturas de composição média de solos da crosta terrestre tabuladas por MASON (1966), com os resultados obtidos por CHOW et al., na região central da Califórnia e assinaturas da ressuspensão do solo em Santiago do Chile obtidas por ARTAXO (1999).

Quando a composição do solo é comparada com medidas de ressuspensão de solo de centros urbanos é esperado um enriquecimento de metais pesados principalmente para $\mathrm{Cu}, \mathrm{Zn}$ e $\mathrm{Pb}$, devido a pavimentação de ruas, queima de óleo combustível, pneus, poeira do asfalto e até mesmo pela contaminação da emissão veicular.

Comparando-se os valores de Ni para a cidade da Califórnia, obtido por CHOW et al., e aos teores obtidos para a cidade de São Paulo (CASTANHO, 1999) podemos observar um aumento na concentração deste metal.

Os teores de Al, Si, K, Ca, Mn e Fe obtidos neste trabalho mostram boa concordância com os valores apresentados para as cidades de Santiago e São Paulo e até mesmo com a assinatura de solo tabulada por MASON (1966).

Quanto ao $\mathrm{Cu}$ e ao $\mathrm{Pb}$ suas concentrações são mais elevadas do que as da assinatura de solos, mas estão próximas as obtidas para as cidades de Santiago, Califórnia e São Paulo.

\section{CONCLUSÕES}

$\mathrm{Na}$ análise de PM10 pode-se observar que no posto do centro da cidade de Campinas a qualidade do ar no que se refere a esse parâmetro vêm aumentado significativamente nos últimos anos. Comparando-se os valores atuais com os determinados por MATSUMOTO (2001) há cerca de seis anos, o aumento do PM10 para a região central trapassando inclusive o valor estabelecido pela CETESB para que a qualidade de ar seja considerada regular que é de $150 \mu \mathrm{g} . \mathrm{m}-3$.

Apesar do monitoramento da qualidade do ar pela CETESB e do aumento das campanhas de conscientização, o ar atmosférico continua a se deteriorar. Tal afirmação é confirmada através dos dados dos elementos analisados por essa pesquisa. $\mathrm{O}$ aumento da industrialização e o sistema de transporte público deficitário são alguns dos fatores que contribuem para a má qualidade do ar na região.

Para o posto de Barão Geraldo os valores ficaram próximos aos determinados no período de 1999-2000 por MATSUMOTO (2001), mostrando que neste local o PM10 não sofreu alteração significativa e os valores estão abaixo do índice de qualidade do ar regular definido pela CETESB. Para o posto de Paulínia os valores de PM10 encontrados são superiores aos do centro de Campinas, com valores também acima do regular.

A determinação das concentrações elementares do material particulado total analisado nas frações grossa e fina por SR-TXRF possibilitaram agrupar os elementos químicos encontrados. O agrupamento efetuado pela análise por ACP e posteriormente pela análise de Cluster permitiu a determinação das componentes principais inferindo aos resultados as distintas fontes de emissão em: veicular, industrial, queima de óleo e re-suspensão de solo.

No posto de Barão Geraldo, a maior contribuição foi de elementos associados à ressuspensão de solo (48\%). Mas neste posto também foram observados elementos de origem industrial e veicular. As emissões industriais contribuíram com $25 \%$ no posto de Barão Geraldo e isto pode ser explida cidade de Campinas foi de aproximadamente 60\%, ul-

\section{cad}

de

a el

\section{A c}

do

poc

vei

Par

val

nad

na

icu.

$\mathrm{Na}$

do

con

poe

No

31 ,

me

à e

trib

por

Foi

ma

as $c$

$\sin$

das

\section{AR}

\section{pos}

150

$\mathrm{CA}$

131

de

$\mathrm{CE}$

$\mathrm{CH}$ 
cado pela proximidade deste posto do pólo petroquímico de Paulínia. Por outro lado neste posto foi verificado que a emissão veicular contribui com $27 \%$ na fração grossa do material particulado.

A contribuição da poeira do solo foi responsável por $79 \%$ do total da fração grossa para o posto de Paulínia, o que pode ser explicado pelo fato do posto de coleta estar localizado próximo a uma área com solo cultivado. A emissão veicular contribui com $21 \%$

Para o posto do Centro de Campinas foi observado um valor de $27 \%$ para as emissões veiculares e $1 \%$ relacionado à queima de óleo combustível. Este fato era esperado visto que o posto do centro de Campinas está localizado na Avenida Anchieta, a qual apresenta um grande fluxo veicular de automóveis e de transporte coletivo.

$\mathrm{Na}$ fração fina do Posto de Barão Geraldo a ressuspensão do solo contribui com $48 \%$, seguida da emissão industrial com $24 \%$ e da veicular com $21 \%$. No posto de Paulínia a poeira do solo é responsável por $44 \%$, a veicular por $36 \%$ e a industrial por $20 \%$ das emissões.

No Centro de Campinas a emissão veicular contribui com $31 \%$ e a poeira do solo contribui com $45 \%$ e é praticamente igual a dos outros postos de coleta. No que se refere à emissão industrial o posto do centro de Campinas contribui com apenas $7 \%$ enquanto que no posto de Barão esta porcentagem é de $24 \%$ e no de Paulínia $20 \%$.

Foi possível avaliar não somente a concentração de PM10, mas outras informações extremamente importantes como as contribuições das fontes emissoras de poluentes. As assinaturas das fontes emissoras foram avaliadas e comparadas com resultados obtidos por outros autores.

\section{REFERÊNCIAS}

ARTAXO, P.; OYOLA, P.; MARTINEZ, R. - Aerosol composition and Source Apportionment in Santiago de Chile. Nuclear Instruments and Methods in Physics Research, v. 150B, p. 409-416, 1999.

CASTANHO, A. D. A. Determinação Quantitativa de Fontes de Material Particulado na cidade de São Paulo. 1999. 131f. Tese de Mestrado - Instituto de Física, Universidade de São Paulo. São Paulo.

CETESB, Relatório da qualidade do ar no Estado de São Paulo - 2001. São Paulo: CETESB. 117p., 2002.

CHOW, J. C.; WATSON, J. G.; HOUCK, J. E.; PRITCHETT, L. C.; ROGERS, C. F.; FRAZIER, C. R.; EGAMI, R. T. - A laboratory Resuspension Chamber to measure Fugitive Dusty Size Distribution and Chemical Composition . Atmospheric Environment . v. 28, n. 21, p. 3463-3481, 1994.

CONAMA. Resolução no 003/1990 - Dispõe sobre padrões de qualidade do ar, previstos no PRONAR. Data da legislação: 28/06/1990 - Publicação DOU (Diário Oficial da União) em 22/08/1990.

EPA - Environmental Protection Agency. Air Quality Criteria for particulate Matter. Volume I. October, 2004.

EPA - U.S. Environmental Protection Agency. Guideline on Speciated Particulate Monitoring. August, 1998.

KLOCKENKÄMPER，R.; KNOTH，J.; PRANGE，A;
SCHWENKE, H. Total reflection $\mathrm{x}$-ray fluorescence spectroscopy. Analytical Chemistry, v. 64, p. 1115A - 1123A, 1992.

LNLS - Laboratório Nacional de Luz Síncrotron na Internet. Disponível em: http://www.lnls.br.

MASON, J. Principles of Geochemistry, John Wiley \& Sons, Nova Iorque, 1966.

MATSUMOTO, E. Estudo da contaminação ambiental atmosférica e de águas superficiais, empregando a fluorescência de raios $X$ dispersiva em energia (ED-XRF) e reflexão total (TXRF). 2001. 148f. Tese de Doutorado Faculdade de Engenharia Civil, Universidade Estadual de Campinas. Campinas.

MELO JÚNIOR, A. S. - Análise quantitativa do material particulado na região de Campinas através das técnicas de microfluorescência de raios $\mathrm{X}$ e reflexão total usando radiação síncrotron. 2007. 284f. Tese de Doutorado - Faculdade de Engenharia Civil, Arquitetura e Urbanismo, Universidade Estadual de Campinas. Campinas.

MOREIRA, S., FAZZA, E. V. - Evaluation of water and sediment of the Graminha and Águas da Serra streams in the city of Limeira (SP-Brazil) by Synchrotron Radiation Total Reflection X-ray Fluorescence. Spectrochimica Acta Part B, v. 63, p. 1432-1442, 2008.

PÉREZ, C. A; RADTKE, M.; SÁNCHEZ, H. J.; TOLENTINO, H.; NEUENSWANDER, R.; BARG, W.; RUBIO, M.; BUENO, M. I. S.; RAIMUNDO, I. M.; ROHWEDDER, J. R. Synchrotron radiation X-ray fluorescence at the LNLS: beamline intrumentation and experiments. Xray Spectrometry, v. 28, p. 320-326, 1999.

SAVAGE, I.; HASWELL, S. J. Multivariate experimental methodology for the evaluation of sample preparation techniques used in simultaneous multielemental analysis using total reflection X-ray fluorescence spectroscopy. Analytica Chimica Acta, v. 376, p. 145-151, 1998.

SCHMITT, M.; HOFFMANN, P.; LIESER, K. H. Perspex as sample carrier in TXRF. Fresenius Zeitschrift für Analytische Chemie, v. 328, p. 593-594, 1987.

SEINFELD, J. H; PANDIS, S. N. Atmospheric chemistry and physics: from air pollution to climate changes. John Wiley \& Sons, New York, 1326p., 1998.

U.S.EPA - U. S. Environmental Protection Agency Guideline for reporting of daily air quality - pollutant standards index (PSI). Office of Air Quality Planning and Standards, 1998. Disponível em: http://www.epa.gov/ttn/ oarpg/t1/memoranda/rg701.pdf. 